\title{
Design and Research of Rectangular, Circular and Triangular Microstrip Patch Antenna
}

\author{
S.Krishna Priya, Jugal Kishore Bhandari, M.Krishna Chaitanya
}

\begin{abstract}
Modern Wireless communication Systems need high gain, light-weight and straightforward structure antennas to assure high potency, quality and additional dependableness. A patch antenna is incredibly easy in building, employing the fabrication techniques of standard Microstrip. It consists of a blotch of metal on a grounded dielectric substrate which forms a light-weight antenna best suited for mobile and aerospace applications. Patch antennas have developed significantly throughout preceding years and plenty of their limitations are overcome by changes in its design and fabrication techniques. The conducting patch may well be of any form however rectangular patterned configuration is used foremost. In this study we tend to have an interest not solely in rectangular however comparison of it with circular and triangular patch antenna styles. The objective here is to analyze the results of various patches.
\end{abstract}

\section{Keyterms: HFSS tool, patch antenna.}

\section{INTRODUCTION}

Antenna is like Eye and Ear of any radio system. A system with no antenna won't have ability to transmit or receive to its full facility. Antenna is the system which receives the radio signal and converts it into lower voltage and when transmitting it converts voltage into radio signal which is electromagnetic wave. An Antenna is a reciprocal device i.e. it can work on a frequency in both directions. Antenna plays a vital role for success of a radio system. Such a lot rests on antenna. Antenna is the component which provides direction to the signal if required. [1]

A Microstrip Antenna (MSA) in its simplest kind consists of a divergent patch on one aspect of a substrate and a ground plane on the other aspect. MSAs are also named as "patch antennas" or "printed antennas" or "planar antennas". Microstrip or patch antennas have become more and more helpful as a result of they are low (paper-thin) profile, planar configuration and conformal structured, robust and light weight. There is ease of fabrication using printed-circuit technology, both Linear and circular (right or left -handed) polarizations is possible (useful for frequency - reuse), they are compatible with modular designs. Hence solid state components can be added directly into the microstrip antenna substrate, which are easily integrable with the circuits; feed lines and matching networks. It is easy to achieve dual-frequency performance and arrays can be easily created to increase directivity. They can be easily mount on satellites, space vehicles and missiles without major alteration and also compatible with MMIC designs.

Revised Manuscript Received on September 14, 2019.

S.Krishna Priya, Associate Professor, Geethanjali college of Engineering and Technology, Hyderabad, Telangana, India.

Jugal Kishore Bhandari, Assistant Professor, Geethanjali college of Engineering and Technology, Hyderabad, Telangana, India.

M.Krishna Chaitanya, -Department of ECE, Geethanjali college of Engineering and Technology, Hyderabad, Telangana, India.
Every element has some limitations so does MSAs have, which are: Low radiation efficiency, small bandwidth, practical limitations on the maximum gain, poor polarization purity, low power handling capability, poor isolation between the feed and also the diverging component, chance of excitation of surface waves, spurious radiation from feeds, junctions and surface waves, high performance arrays need complicated feed systems[2].

Microstrip patch antenna has many applications. a number of these applications are: Mobile and satellite communication application, Global Positioning System applications, Worldwide ability for Microwave Access (WiMax), measuring device Application, Rectenna Application, Telemedicine Application, medicative applications of patch. [3]

To fabricate an antenna, first we select the frequency of operation, the substrate used and thickness of the substrate. The shape of the antenna is determined and then from these the dimensions of the substrate and patch are calculated. The antenna is designed and simulated in software. After obtaining the desired results, the actual fabrication process starts. Here HFSS software is used for simulation. Different shapes of the patch are designed for obtaining the best results and the same is concluded.

\section{EXPERIMENTAL}

\section{A. DESIGN OF MICROSTRIP PATCH ANTENNA:}

Design of Microstrip Patch Antenna involves the idea of dimensions of the patch from the knowledge of resonant frequency in $\mathrm{Hz}$.

Firstly we have taken length of patch as $32 \mathrm{~mm}$, breadth as $30 \mathrm{~mm}$ and then its area is equated to area of circle and corresponding radius is calculated. Radius is calculated as $17.4 \mathrm{~mm}$.

The simulation is accomplished on HFSS (High frequency structure simulator) software. HFSS is high performance electromagnetic field simulator with 3D volumetric view of passive device modeling that gives advantages accustomed with Microsoft Windows GUI. It integrates solid modeling, visualization, simulation, automation with easy to learn environment. Typical uses of HFSS are: designing, simulation and package modeling of EMC/EMI, connectors, waveguide, antennas for mobile communications, PCB board modeling and filters. HFSS uses finite element method a numerical technique and is a procedural simulator. In this a structure is subdivided into various smaller subsections called as finite elements such as tetrahedral and complete collection of tetrahedral called as

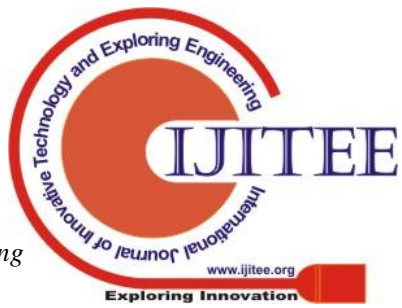


mesh. For these finite elements Solution is found for the fields within the finite element. And these solutions are interrelated so that Maxwell's equations are satisfied across the inter elements, which can yield a field solution for the entire inventive structure. Once the field solution is establish the s-matrix solution is determined. [4]

\section{B. SIMULATIONS:}

- After designing the single band linearly Polarized Micro Strip antenna the simulations are performed.

- First Validation check is performed to observe warnings and errors if any in the design.

- Next the setup is assigned to the antenna, which includes operating frequency band 2.60-2.85 GHz sweep in the range $1-4 \mathrm{GHz}$ with $0.01 \mathrm{GHz}$ step.

- Results for return loss, VSWR, gain and other parameters of antenna are obtained from the generate report section of HFSS tool.

Boundaries and excitations of the Microstrip antenna:

Perfect E: Patch, Ground

Radiating only: Air (except bottom face)

Excitation: Wave port (port 1)

C. FORMULAE FOR DIMENSIONS RECTANGULAR PATCH ANTENNA:

Calculation of W (Width):

$$
W=\frac{c}{2 f o \sqrt{\frac{\left(E_{r}+1\right)}{2}}}
$$

The above equation gives the width of the micro strip patch antenna.

On substituting, $\mathrm{c}=3 \times 10^{11} \mathrm{~mm} / \mathrm{sec} ; \mathrm{f}_{\mathrm{o}}=2.72 \mathrm{GHz}, \varepsilon_{\mathrm{r}}=$ 2.94; so $\mathrm{W}=30 \mathrm{~mm}$..

Calculation of Leff (Effective Length):

$$
L_{\text {eff }}=\frac{c}{2 f o \sqrt{\epsilon_{\text {reff }}}}
$$

The above equation gives the effective length of the micro strip patch antenna.

On substituting, $\mathrm{c}=3 \times 1011 \mathrm{~mm} / \mathrm{sec}$; fo $=2.72 \mathrm{GHz}$, غreff $=2.60$; so Leff $=34 \mathrm{~mm}$.

D. FORMULA FOR RADIUS OF CIRCULAR PATCH ANTENNA:

$$
\mathrm{r}=\frac{1.8412}{2 \pi \mathrm{f} \sqrt{\varepsilon_{\mathrm{r}} \sqrt{\mu_{\mathrm{o}} \varepsilon_{\mathrm{o}}}}}
$$

Where, $\mathrm{f}=2.72 \mathrm{GHz}, \varepsilon_{r}=2.94, \mu_{o}=1.25 \times 10^{-6}$ , $\varepsilon_{0}=8.85 \times 10^{-12}$, so $\mathrm{r}=18.8 \mathrm{~mm}$.

\section{E. FORMULA FOR SIDE LENGTH OF TRAINGULAR} PATCH ANTENNA:

The equilateral triangular patch has a substrate of thickness ' $h$ ' with side length ' $S$ ' on with relative dielectric constant ' $\in$ r'.

The below equation gives the resonant frequency of ETMA with side length S

$$
\mathrm{f}_{\mathrm{mn}}=\frac{2 \mathrm{c} \sqrt{\mathrm{m}^{2}+\mathrm{n}^{2}+\mathrm{mn}}}{3 \mathrm{~S}_{\mathrm{e} \sqrt{\epsilon_{0}}}}
$$

Where, $S_{e}$ is the effective side length given by,

$$
S_{e}=S+\frac{h}{\sqrt{\epsilon_{e}}}
$$

Where, $\epsilon_{e}$ is the effective dielectric constant given by,

$$
\epsilon_{e}=\frac{\epsilon_{r}+1}{2}+\frac{\epsilon_{r}-1}{2}\left[1+\frac{10 h}{\frac{s}{2}}\right]^{\frac{-1}{2}}
$$

Where, $\mathrm{h}$ is the height of the dielectric substrate and $\epsilon_{r}$ is the dielectric constant.

Therefore, we obtain the side as $45 \mathrm{~mm}$.

\section{SIMULATION RESULTS}

\section{A. SIMULATION RESULTS OF RECTANGULAR PATCH ANTENNA}

The figure below gives the shape, VSWR, gain, return loss, and other parameters of the rectangular Microstrip antenna.

Values of parameters are,

$\begin{array}{llll}\text { Return loss } & = & & -13.48 \mathrm{~dB} \\ \text { VSWR } & & = & 1.53 \\ \text { Gain } & = & 2.3 & \\ \text { Radiation efficiency } & = & 99 \%\end{array}$

The dimensions used in tool to design the patch antenna are approximate values and are almost near to the calculated values.

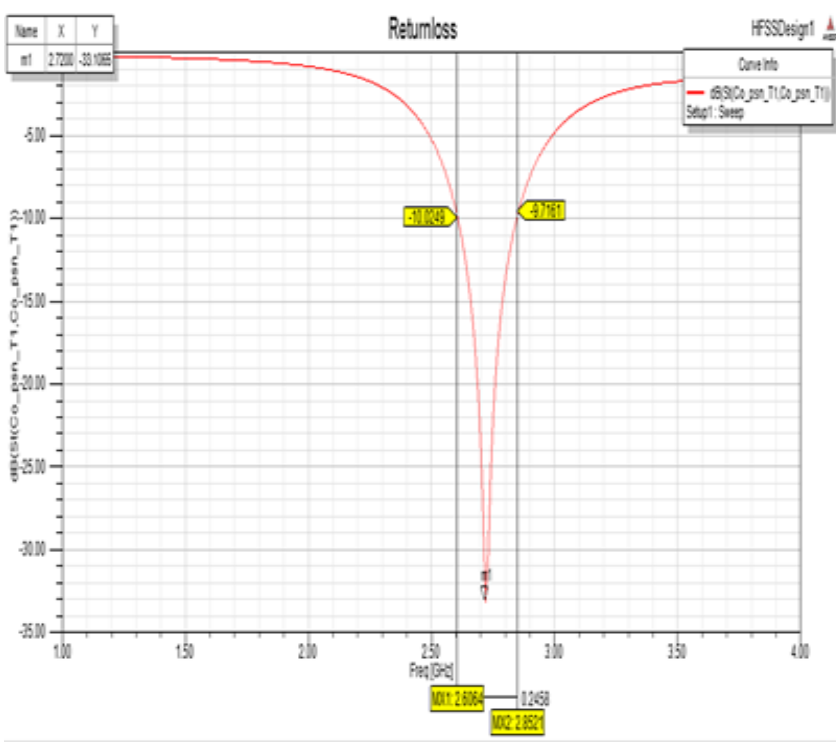

Fig 1: $S_{11}$ Graph for designed rectangular patch antenna 


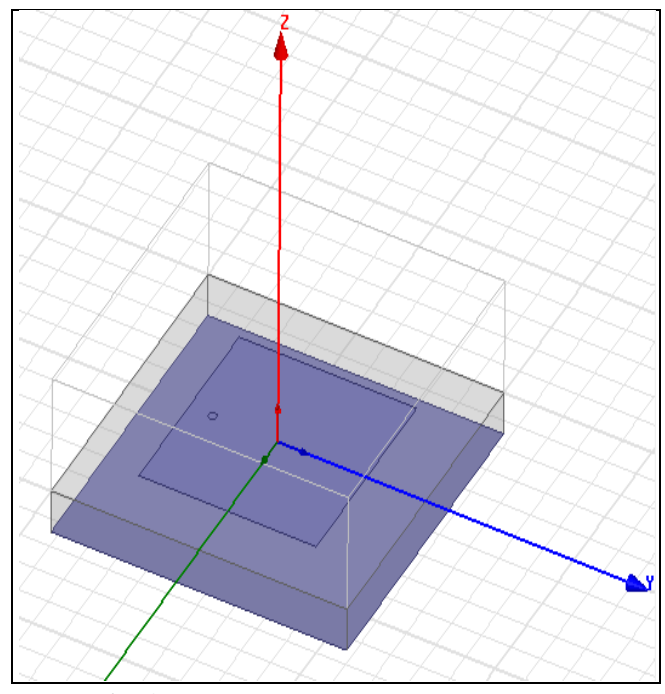

Fig 2: Rectangular patch antenna

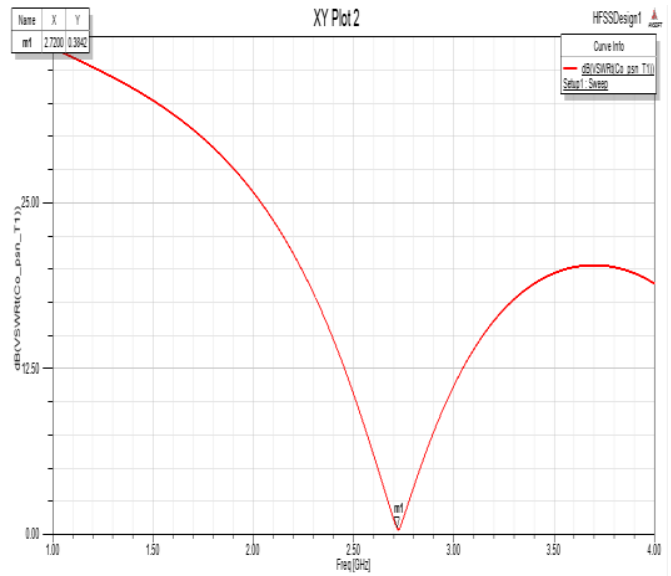

Fig3: VSWR graph for designed rectangular patch

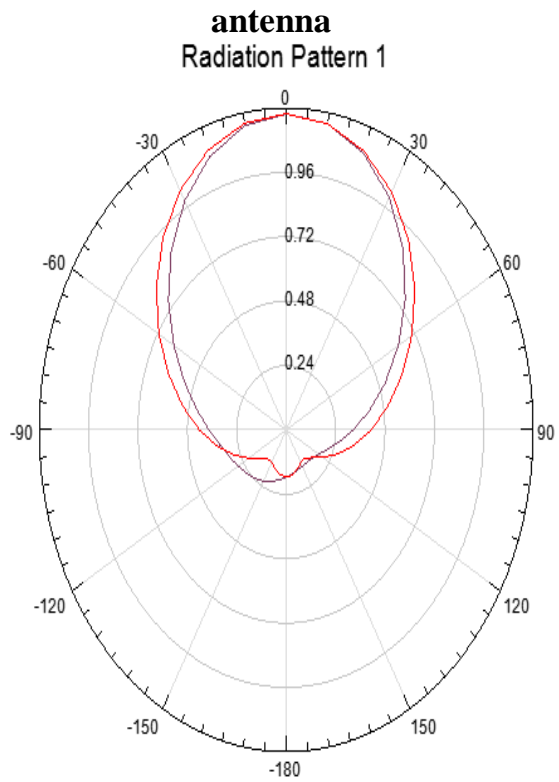

Fig 4: Radiation pattern of designed rectangular patch

$\begin{array}{llll}\text { VSWR } & = & 0.38 \\ \text { Gain } & = & 2.38 & \end{array}$

\begin{tabular}{|c|c|c|}
\hline \multicolumn{3}{|l|}{ - Inputs- } \\
\hline Setup Name: & Infinite Sphere1 & OK \\
\hline Solution: & Lastiddaptive & \\
\hline Array Setup: & None & Export \\
\hline Intinsic Variation: & Freq='2.72GHz' & \\
\hline Design Variation: & brea='32mm' bread='30mm' f' & Export Fields \\
\hline \multicolumn{3}{|l|}{ Antenna Parameters: } \\
\hline Quantity & Value & Units \\
\hline MaxU & 0.0018403 & $\mathrm{~W} / \mathrm{st}$ \\
\hline Peak Directivity & 2.4107 & \\
\hline Peak Gain & 2.3882 & \\
\hline Peak Realized Gain & 2.2856 & \\
\hline Radiated Power & 0.0095934 & W \\
\hline Accepted Power & 0.0096837 & W \\
\hline Incident Power & 0.010118 & W \\
\hline Radiation Efficiency & 0.99067 & \\
\hline Front to Back Ratio & 44.838 & \\
\hline Decay Factor & 0 & \\
\hline
\end{tabular}

Fig 5: Parameters of designed rectangular patch antenna

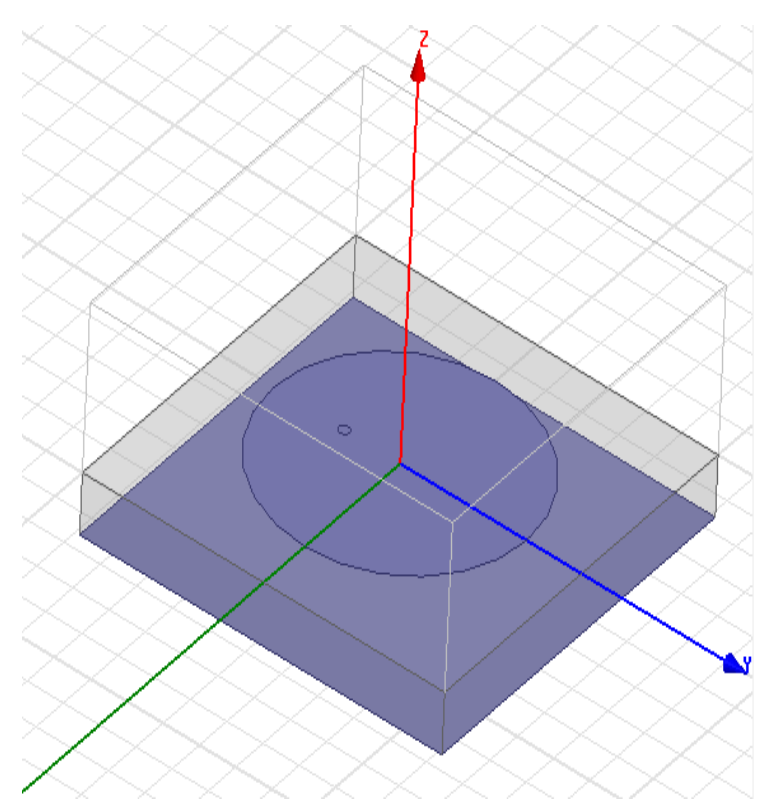

Fig 6: Circular Patch Antenna

B. SIMULATION RESULTS OF CIRCULAR PATCH ANTENNA:

The figures 5.6 - 5.10 give the shape, return loss, VSWR, gain, various parameters of the rectangular Microstrip antenna. Values of parameters are given below.

Return loss

$=\quad-33.1 \mathrm{~dB}$ 


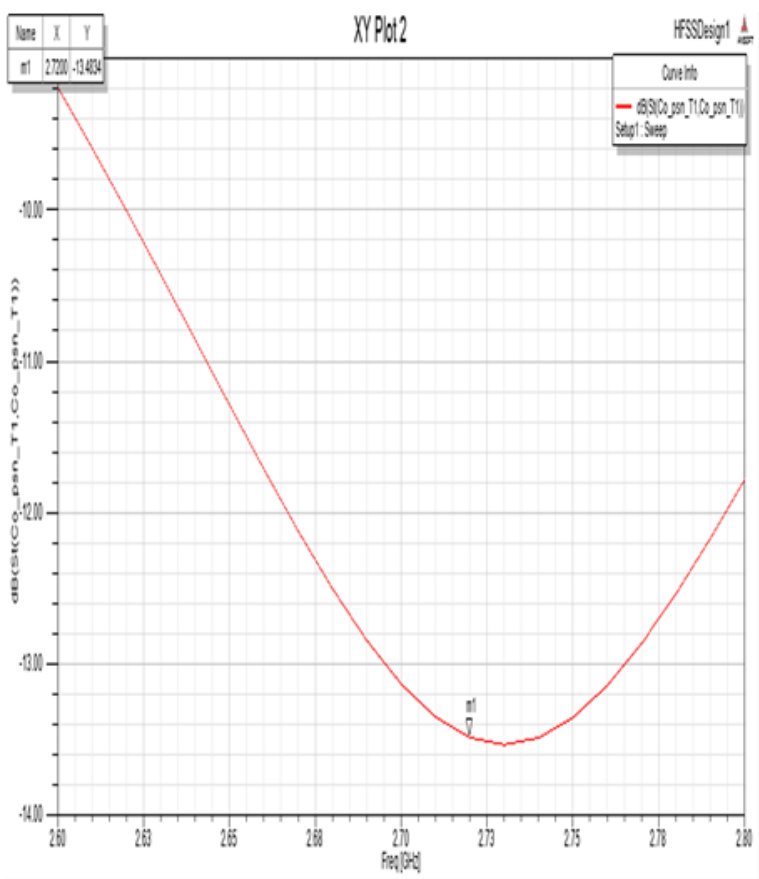

Fig 7: $S_{11}$ Graph for designed circular patch antenna

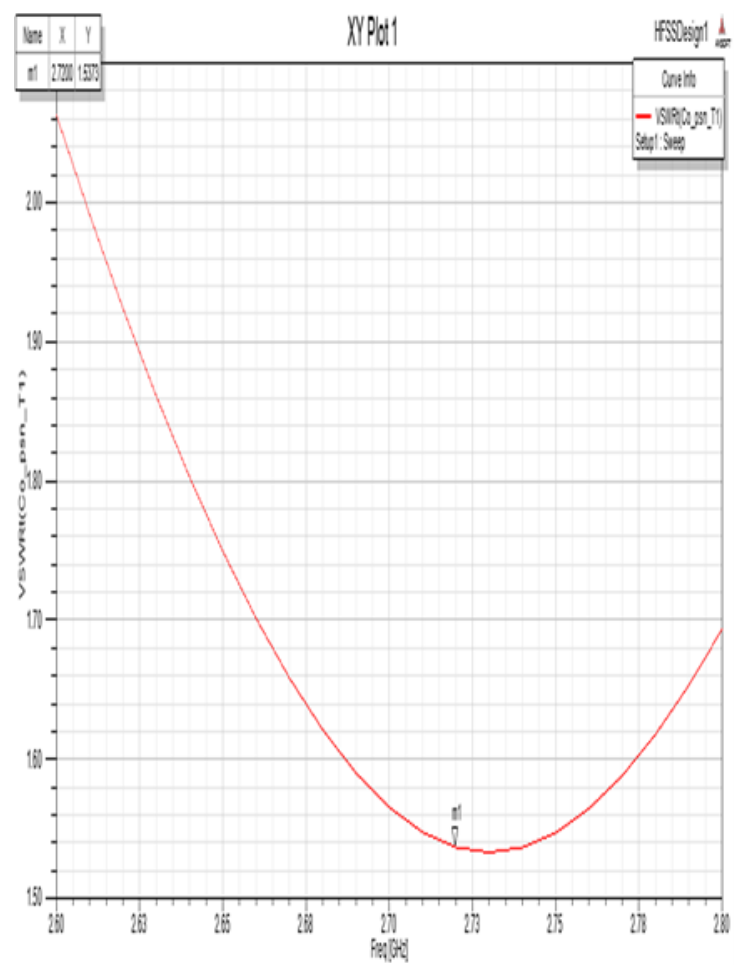

Fig 8: VSWR graph for circular patch antenna

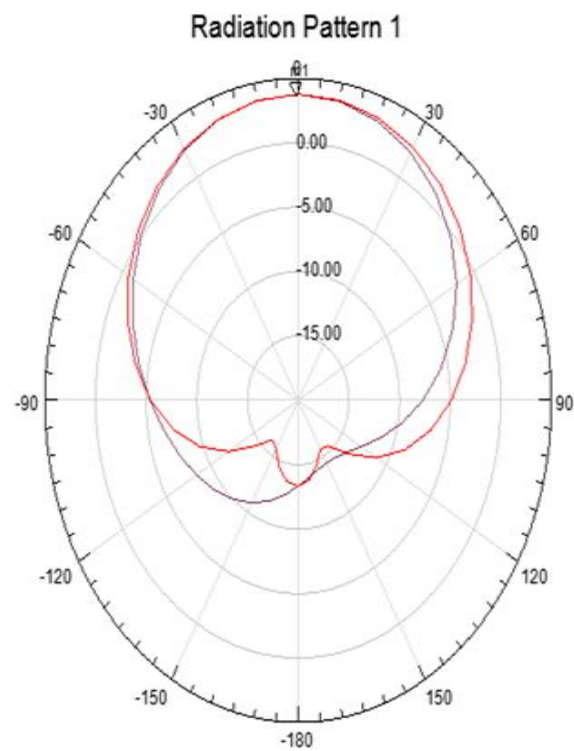

Fig 9: Radiation Pattern of designed circular patch antenna

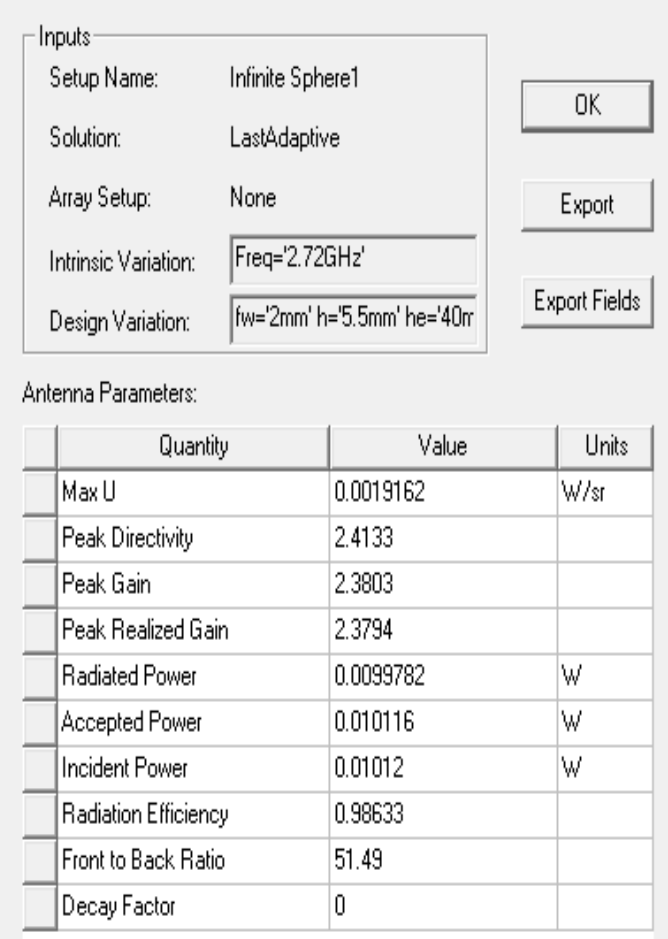

Fig 10: Parameters of designed circular patch antenna C. SIMULATION RESULTS OF TRIANGULAR PATCH ANTENNA:

The figures give the shape; return loss, VSWR, gain, various parameters of the rectangular microstrip antenna. Values of parameters are given below.

$\begin{array}{llll}\text { Return loss } & = & & -33.1 \mathrm{~dB} \\ \text { VSWR } & & = & 0.38 \\ \text { Gain } & = & 2.38 & \end{array}$




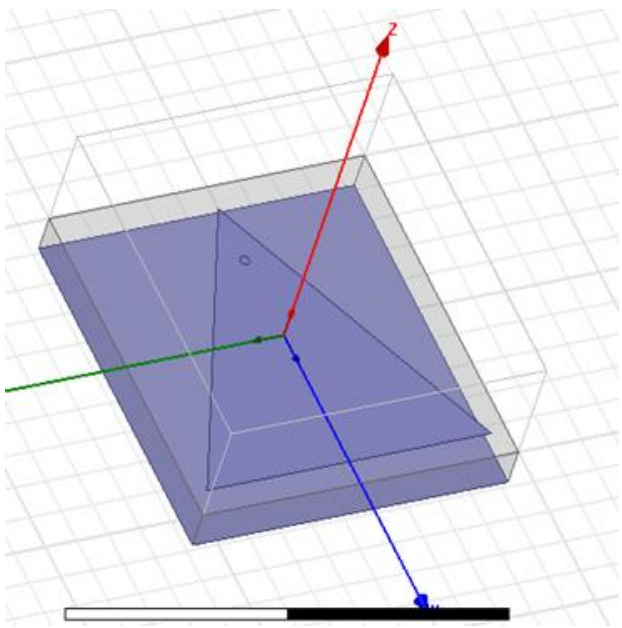

Fig 11: Triangular Patch Antenna
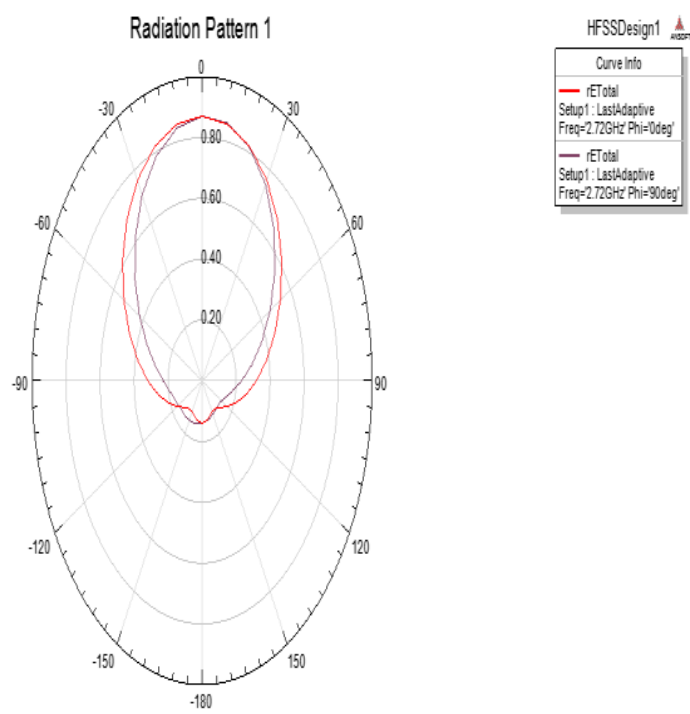

Fig 12: Radiation Pattern of designed triangular patch antenna

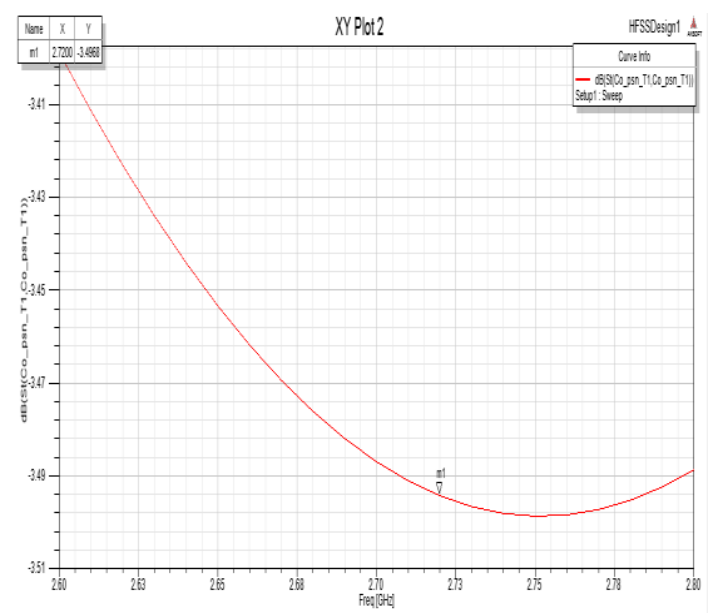

Fig 13: $S_{11}$ Graph for designed triangular patch antenna

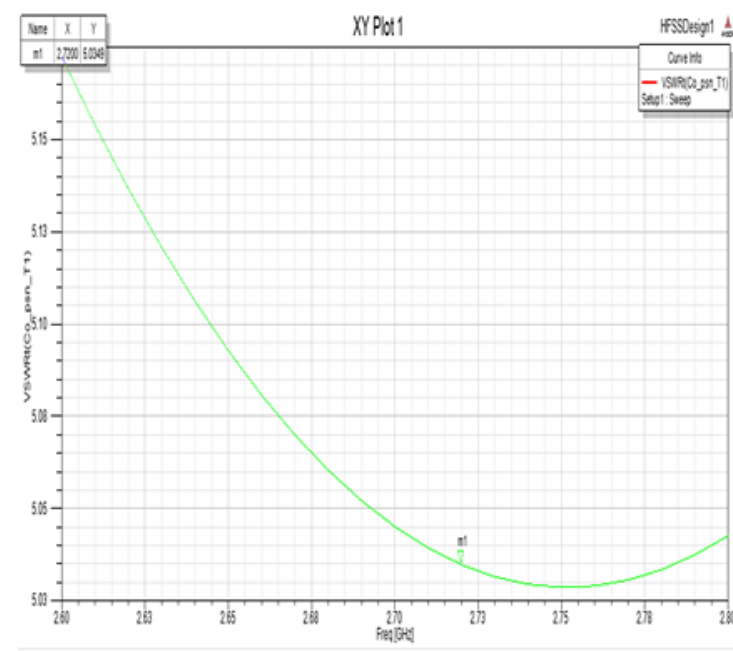

Fig 14: VSWR graph for triangular patch antenna

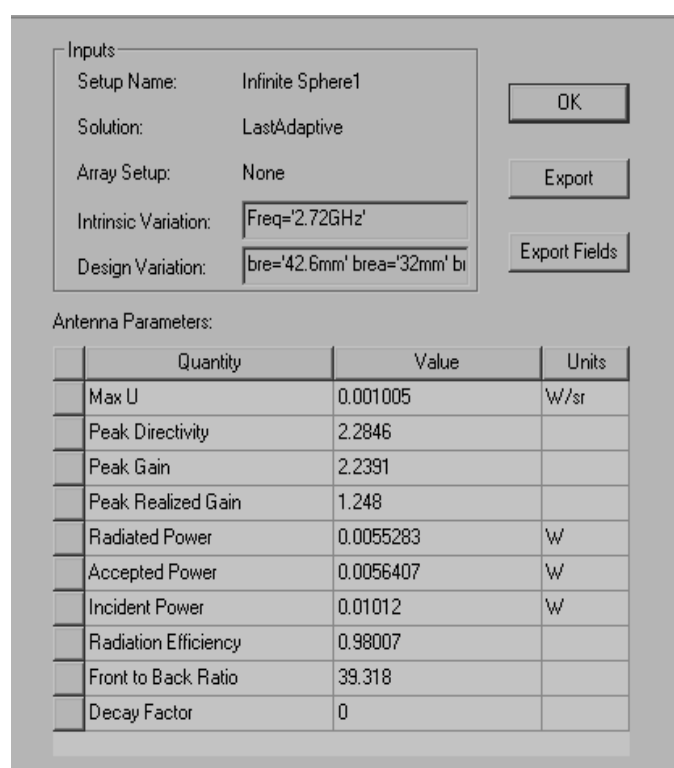

Fig 15: Parameters of designed triangular patch antenna

\section{ANALYSIS AND COMPARISION}

First microstrip antenna with rectangular shape has been considered and simulated. This is done by calculating length and breadth of the antenna using specified formulae. The performance of the antenna has been evaluated using results After this, circular shape antenna has been designed. Approximate radius of circular patch antenna is calculated by using the specified equation. The simulation is done for the circular patch and results are obtained. Next, triangular shape antenna has been designed. Approximate side length of triangular patch antenna is calculated by applying the specified equation. The simulation is done for the triangular patch and results of three antennas are compared. Finally conclusion may be given as circular patch is more appropriate in terms of optimized parameters. The table gives the comparison of rectangular, circular and triangular patch antennas. 


\section{CONCLUSION}

This paper offers the design, Simulation and performance comparison of circular, triangular and rectangular patch antennas. These designed antennas are of better directivity, high gain and improved impedance. These parameters are attained with improved less increase in the wideness of the antenna structure. The considerable enhancement in the directivity, High Power Beam width is the main achievement of the projected work. This designed antenna may attest to be a useful structure in recent wireless satellite communication systems, where circular polarized radiations which provide higher axial ratio bandwidth are preferred. In simulation frequency of $2.72 \mathrm{GHz}$ for calculation of desired parameters of circular, triangular and rectangular patches.

\begin{tabular}{|l|l|l|l|}
\hline Parameter & $\begin{array}{l}\text { Rectangular } \\
\mathrm{Mm}\end{array}$ & $\begin{array}{l}\text { Circular } \\
\mathrm{Mm}\end{array}$ & $\begin{array}{l}\text { Triangle } \\
\mathrm{Mm}\end{array}$ \\
\hline $\begin{array}{l}\text { Dimensions } \\
(\mathrm{mm})\end{array}$ & $\begin{array}{l}\mathrm{L}=32, \\
\mathrm{~B}=30\end{array}$ & $\mathrm{R}=17.4$ & $\begin{array}{l}\mathrm{B}=45, \\
\mathrm{H}=42.6\end{array}$ \\
\hline $\mathrm{S} 11(\mathrm{~dB})$ & -13.5 & -33 & -3.49 \\
\hline $\begin{array}{l}\text { VSWR(dB) } \\
\text { Feed Position }\end{array}$ & $0,-11,0$ & $0,-$ & $0,-12.6,-$ \\
\hline $\begin{array}{l}\text { Directivity } \\
(\mathrm{dB})\end{array}$ & 2.4 & $7.74,0$ & 5.5 \\
\hline Gain (dB) & 2.38 & 2.4 & 2.28 \\
\hline
\end{tabular}

Table 1: Comparison of various parameters of designed rectangular, circular and triangular patch antenna

From the above table we conclude that circular patch antenna is the most efficient patch design than rectangular and triangular patch antennas in comparing the parameters such as VSWR, directivity and radiation pattern. For far better results the value of dielectric constant should be lowered. Circular patch has wide applications and is always of use where compact antennas are required and as well as desired patch antenna for several wireless and satellite applications.

\section{FUTURE SCOPE}

Manual calculations of parameter are complex for all types of patch antennas. The GUI can be used to analyze the influence of the Changes in input parameters on radiation pattern and also gives Ease in Calculations. Due to changes in the material of the patch, physical parameters of the Microstrip Patch changes (mentioned in results). This could help the designer in determining the antenna performance and make necessary adjustment before fabricating the antenna structure. There are many antenna design simulators. One of them is MATLAB which is very challenging as it uses very complex programming to achieve the desired results and requires more time for simulations. But, this can be effortlessly solved by use of software tools available for RF simulation. Some of them are Zealand IE3D and HFSS. Further work on design and simulation can be carried out by use of such advanced software's with additional 3D volumetric view options.

Calculation of directivity, gain, High Power Beam width, characteristic Impedance, is done. A further study can be done on designing of UHF frequency operating microstrip patch antenna, further improving directive or gain to meet the demand for long distance communications providing a fixed beam of specified shape (beam shape) or a beam that scans in response to system stimulus.

\section{REFERENCES}

1. https://www.quora.com/What-is-the-importance-ofantenna

2. https://www.quora.com/What-is-a-microstrip-patchantenna-What-are-its-applications

3. Indrasen Singh, Dr. V.S. Tripathi , Micro strip Patch Antenna and its Applications: a Survey, Vol 2 (5), 1595 1599

4. https://www.quora.com/What-is-HFSS

5. https://www.hindawi.com/journals/ijap/si

6. C.A. Balanis, "Antenna Theory, Analysis and Design" John Wiley \& Sons, New York, 1997. 